Article

\title{
Sustainability and Consumer Willingness to Pay for Legumes: A Laboratory Study with Lentils
}

\author{
Stéphan Marette
}

check for updates

Citation: Marette, S. Sustainability and Consumer Willingness to Pay for Legumes: A Laboratory Study with Lentils. Sustainability 2021, 13, 3408. https://doi.org/10.3390/su13063408

Academic Editor: Anna Irene De Luca

Received: 19 February 2021

Accepted: 16 March 2021

Published: 19 March 2021

Publisher's Note: MDPI stays neutral with regard to jurisdictional claims in published maps and institutional affiliations.

Copyright: (C) 2021 by the author. Licensee MDPI, Basel, Switzerland. This article is an open access article distributed under the terms and conditions of the Creative Commons Attribution (CC BY) license (https:/ / creativecommons.org/licenses/by/ $4.0 /)$.
UMR Economie Publique, AgroParisTech, INRAE, Université Paris-Saclay, 78850 Grignon, France; marette@agroparistech.fr

\begin{abstract}
We performed a laboratory study in France to explore consumer reactions to information about lentils, a legume whose consumption is sustainable and recommended by nutritionists and environmentalists. More specifically, we examined the effect of informational messages on consumer willingness to pay (WTP) for lentils bearing different production labels. Study participants were given two generic messages designed to promote lentils as a general product with nutritional and environmental benefits. These messages were followed by two specific messages related to one lentil packet with revealed information about the use of certain agricultural practices (e.g., intercropping, organic and local production, and producer partnerships). Initial WTP were measured before the information was provided. The results show that labeling had a strong influence on initial WTP. When WTP were measured after the participants had received the generic and specific informational messages, we observed a weak but significant influence for the lentils with organic and local production labels. There was no effect for the lentils without any production labels. We thus conclude that providing generic information via official recommendations and further developing legume labeling systems could act synergistically to drive some weak changes in consumer choices.
\end{abstract}

Keywords: experimental economics; consumer behaviour; nutrition; environment

\section{Introduction}

In many countries, there is extensive scientific debate regarding the impacts of food production systems on agriculture and biodiversity, which has given rise to diverse recommendations for improving agricultural practices. Several research institutes have proposed crop diversification as a solution for reducing pesticide and chemical fertilizer use [1]. Such a strategy would help reverse the historical trend toward intensification and monoculture, creating some environmental problems [2]. Indeed, many empirical studies have shown that crop rotations have become greatly simplified over recent decades [3].

Cultivating legumes (whose edible seeds are known as pulses) is often recommended as a strategy for promoting crop diversification and sustainability. Legumes can fix atmospheric nitrogen thanks to their root nodules. This nitrogen is then released into the soil, allowing farmers to reduce their reliance on synthetic nitrogen fertilizers and pesticides, which yields environmental benefits [4]. Moreover, increasing diversity in cropping systems with more legumes helps balance farms' profitability and environmental concerns, and it also reduces weeds invasions. However, many technical barriers to legume farming remain, such as the lack of technical knowledge among farmers and the difficulties involved in building dedicated supply chains [5]. These issues impede the expansion of legume farming in OECD countries. In Europe, the importance of legume crop species grown is generally limited because of various barriers [6], and the share of legume crops differs widely from one country to another, which is driven by various cultural and environmental influences. Another major reason for the low levels of legume cultivation is the relatively modest demand for legumes by consumers in OECD countries [7].

It may be that consumers in OECD countries fail to eat legumes for a variety of reasons: they lack information about the benefits of legumes, they have not incorporated 
legumes into their regular dietary habits, or they do not have commercial access to diverse legume products. However, this food type, which includes lentils, peas, and beans, is a good source of fiber and proteins [8]. In many European countries, the consumption of dry legume seeds including legumes is residual, and many of these species are not even known by consumers [9]. Such a situation raises major questions related to their intakes and the type of proteins they contain. Legumes are among the best plant-based sources of proteins [8]. However, essential nutrients are hard to obtain in a vegetarian diet and most plant foods only partially offer some of the nine essential amino acids. It is recommended that vegetarians and vegans eat legumes and nuts daily, along with wholegrain cereals and pseudo-cereals, to ensure adequate nutrient intakes [10]. This question was not tackled in the revealed messages of this experiment, since neither vegetarian nor vegan participants were recruited in this experiment. Indeed, all our participants declared they were eating animal-based foods (see the next section).

Legumes can partially replace animal proteins, which are overconsumed by urban populations around the world. Increasing the proportion of legumes in people's diets may help shift nutritional intake in a healthier direction [11]. The challenge consists in developing alternative dietary regimes that are acceptable to consumers and that replace unhealthy and environmentally harmful eating habits, like the excess of meat or dairy consumption, with healthy and environmentally friendly habits like the consumption of fruits, vegetables, and legumes [12,13]. While many studies have focused on how to effectively carry out substitutions among broad food categories, like swapping out meat for fruits and vegetables, to promote more sustainable diets [14,15], very few studies have focused on how consumers change their perceptions of individual food types after being informed of the latter's nutritional and environmental benefits.

This study examined how consumers responded when they learned about the above sustainable benefits associated with a specific food category: dried lentils. This pulse (or legume) is already eaten by some consumers, but nutritionists and environmentalists recommend that it should be consumed in greater quantities. Using a laboratory experiment in France, we evaluated how generic and precise informational messages affected study participants' willingness-to-pay (WTP) for lentils. By using controlled conditions, we were able to obtain WTP estimates from participants who had been able to carefully form their opinion of the product's value. We could also precisely control the information shown to participants [16]. Such lab results can complement results from field experiments characterizing consumer behavior in stores, where other factors are at play, including the abundance of product messages, consumer (in-)capacity for recall, time limitations on purchasing decisions, the number of intended purchases, and/or the confusion induced by complex information.

Following the Becker, DeGroot, and Marschak (BDM) procedure [17], a five-stage experiment was conducted in France in October 2019. Participants were shown three packages of lentils with different characteristics and different labels and presented with the option to purchase one of them. The experiment used a within-subject design: each participant received all the informational messages, namely generic and specific information. In this paper, the distinction between generic and specific messages reflects the difference between generic advertising and specific brand advertising. Indeed, while generic advertising is designed to promote a general product and its consumption advantages with a general message like "Eating fruits or vegetables is good for your health", specific/private advertising focuses on one specific brand name. The design of this paper made it easier to determine how participants adjusted their WTP according to these different types of messages, namely the generic one linked to lentils in general and the specific one linked to a precise packet/brand.

The results show that initial WTP (i.e., before any information was provided) was significantly affected by lentil labeling. They also indicate that the generic and specific messages had a weak but significant effect on WTP for the lentils bearing both the organic and local production labels; there was no effect on the label-free lentils. These findings 
indicate that providing generic information via official recommendations and further developing food labeling systems should serve as synergistic actions.

Our research falls squarely into the body of work being carried out on dietary habits, food diversity, and sustainability. Traditionally, official recommendations address diets in their entirety and make suggestions regarding broad categories of foods, namely meat, fruits, vegetables, and/or legumes [13]. We took a different approach in our study, choosing to focus on a specific food type: lentils. Additionally, the form in which the lentils were presented to participants-as dried pulses-differed from the form in which lentils have been presented in other studies, where they have been incorporated into newer, trendier foods such as veggie burgers, veggie sausages, and non-dairy cheeses, which are often made with grains and legumes (e.g., peas, lentils, and beans) and which compete directly with meat products [18-21].

This study provides insight into how consumers perceive crop diversification and sustainability. In past work on vegetables, one recent paper [22] found that WTP for diversity within food systems was relatively low. Another paper [23] discovered that consumers were somewhat willing to increase their monthly food expenditures to ensure that products came from systems that employed crop diversification and that protected biodiversity. Our study differs from the above research in that it focused on WTP for a single product, lentils, and provided participants with information on the food's nutritional and environmental benefits. Our findings concur with those of [22], as we observed a relatively low WTP for products from diversified agricultural systems.

Our work also sheds light on the influence of informational messages. The first set of "generic" messaging that we used served as a form of generic advertising, aiming to promote the consumption of a general product type, namely the lentils and their general benefits. Previous studies have highlighted that conveying generic information could be counterproductive in the case of high-quality foods because it negatively influences the perception of quality and minimizes product differentiation. Previous research by [24-26] has shown that a company producing higher-quality goods could be harmed by generic marketing when competing with companies selling lower-quality goods. In contrast, we observed that our generic informational messages had a weak positive effect for lentils with organic and local production labels and no effect on low-quality lentils without any label. Environmental messaging appears as a complement and reinforced the positive perception of these labels.

This manuscript is organized as follows: The methods are described in Section 2, the results are presented in Section 3, and the conclusions are laid out in Section 4.

\section{Materials and Methods}

This section successively details the sample selection, the offered products, the experimental timeline, the BDM mechanism determining the purchases, and the revealed information to participants.

\subsection{The Sample Selection}

We conducted the experiment in Dijon, Burgundy (Bourgogne), France, in multiple 1-hour sessions in October 2019. The sample consisted of 127 persons aged between 18 and 65 years. This sample of 127 participants was randomly selected based on the quota method and was representative for age groups and socio-economic status for the population of the city.

Participants were recruited through the Chemosens PanelSens database built by the Centre des Sciences du Goût et de l'Alimentation, INRAE Dijon.

During the recruitment, participants were informed that the experiment will focus on food without any tasting procedure, and it would last about 1 hour with a $€ 10$ indemnity. Each experimental session included between 14-16 participants and lasted $50 \mathrm{~min}$. Table 1 presents some participants characteristics. Table 1 shows the absence of habits regarding the consumption for lentils and more generally for legumes, while meat is frequently 
consumed. This low consumption of lentils is aligned on the habits of western countries, in which citizens' intakes of legumes are lower than nutritional recommendations $[7,27]$.

Table 1. Sociodemographic and some dietary habits of 127 participants.

\begin{tabular}{|c|c|c|}
\hline Gender & $\begin{array}{l}\text { Women }(\%) \\
\text { Men }(\%)\end{array}$ & $\begin{array}{l}50.3 \\
49.7\end{array}$ \\
\hline Age (year) & $\begin{array}{c}20-34(\%) \\
35-49(\%) \\
\text { Age } 49 \text { and over }(\%)\end{array}$ & $\begin{array}{c}26.8 \\
26 \\
47.2\end{array}$ \\
\hline Level of education ${ }^{1}$ & $\begin{array}{c}<\text { Baccalaureate }(\%) \\
\text { Bac and bac }+2(\%) \\
\text { Higher than bac }+2(\%)\end{array}$ & $\begin{array}{l}12.5 \\
45.6 \\
41.9\end{array}$ \\
\hline I eat lentils & $\begin{array}{l}\text { Twice a week or more }(\%) \\
\text { Less than twice a week (\%) }\end{array}$ & $\begin{array}{c}7.8 \\
92.1\end{array}$ \\
\hline I eat meat & $\begin{array}{l}\text { Twice a week or more (\%) } \\
\text { Less than twice a week }(\%)\end{array}$ & $\begin{array}{c}92.9 \\
7.1\end{array}$ \\
\hline
\end{tabular}

Note: from the exit questionnaire. ${ }^{1}$ Baccalaureate (bac): French high school diploma.

\subsection{The Offered Products}

Our experiment focused on three different packets of lentils with a $500 \mathrm{~g}$ weight that is a standard in France. From observations in supermarkets in the Dijon area right before the experiment, we selected three products that tried to reflect the diversity of brands and labels offered by supermarkets. Figure 1 shows the packets offered to participants, namely the Conventional one on the left, the Organic one (Bio) in the middle, and the Organic\&Local one (Bio and Bourgogne) on the right, with specific lentils produced by the COCEBI cooperative and coming from Bourgogne, the Dijon region in which this experiment was conducted.

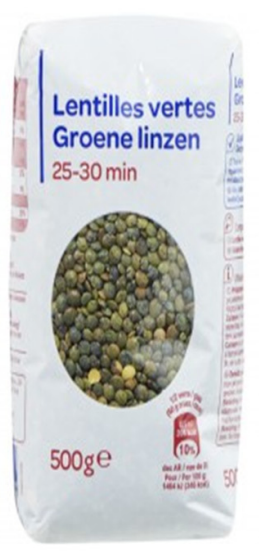

Conventional

Observed

price in stores, $\quad P=€ 0.79$ not revealed in the lab

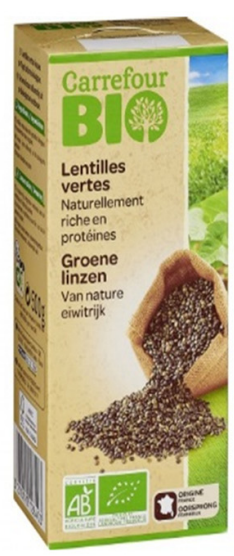

Organic (Bio)

$P=€ 1.93$

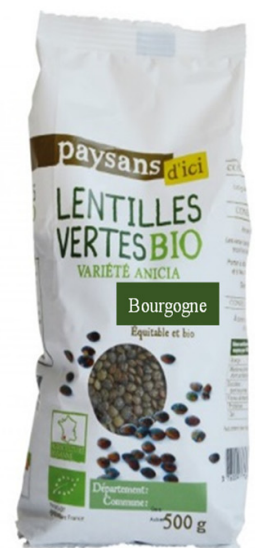

Organic (Bio) \& Local (Bourgogne)

$P=€ 2.80$

Figure 1. The three packets of lentils (500 g) offered to participants.

Several points can be noticed regarding these products. First, it was indicated that Conventional lentils were packed in France without more details on the packet, implicitly meaning that they were grown abroad and imported in France. Even if the precise origin of the cultivation was not detailed, it is likely that they were coming from Canada. 
Moreover, the second packet, Organic, was offered by a private label, namely Carrefour, a French major international retail chain. This second packet precisely indicated the French origin of lentils with a logo, which could also characterize this organic product as a "local product". However, for this paper, we restricted the local denomination to the third packet, Organic\&Local, with lentils coming from Bourgogne, the specific region in which this experiment was conducted. In other words, the second packet can be seen as a national product, while the third one appears as a regional product, being a priori "more local" than the national packet.

On Figure 1, the average observed prices $\mathrm{P}$ in supermarkets at the time of the experiment indicate the diversity of products offered to consumers. These average observed prices $\mathrm{P}$ were not revealed to participants for avoiding any influence or anchorage effect in the WTP elicitation. It is interesting to note that this range of observed prices indicated in Figure 1 reflects the product differentiation observed on the French market, when we took into account regular and organic shelves in supermarkets. The various-quality labels lead to important differences in prices. Each participant faced these 3 products on her/his table, she/he/they entered the lab without any additional information.

\subsection{Experimental Timeline}

The timing of the 1-hour experiment was as follows.

At the beginning of the experiment, some initial explanations were read. We insisted on the fact that all replies were anonymous, since participants will be only identified by a number for the rest of the session. No information was revealed about observed prices in supermarkets. We informed them that we added $€ 5$ to the initial $€ 10$ indemnity (announced in the recruitment) to allow for the possible purchase of one packet at the end of the session with the $€ 15$. Explanations of the BDM mechanism were given, as explained in the next subsection, and a trial of the BDM procedure was conducted with a candy bar. Participants signed a consent form that summarized the explanations.

The lab experiment was conducted in five successive rounds. In round \#1, no precise information about packets and observed average prices of packets was given, and the initial WTPs were elicited for each packet.

In rounds \#2,\#3, \#4, and \#5, four explanatory messages were successively revealed before the elicitation of the WTPs for each packet after each message.

At the end of the experiment, participants completed an exit questionnaire on food issues and sociodemographic variables. The experiment concluded by determining whether the participants will take one lentil packet away with them according to the BDM procedure that is now presented.

\subsection{The BDM Mechanism for Determining WTP}

To elicit participants' WTP for one packet, our experiment used the Becker, DeGroot and Marschak (BDM) mechanism [17]. Over the five rounds, the exact question for each product was as follows: "What is the maximum price you are willing to pay for this product?" For each round, a paper sheet given to participants was presenting the pictures of three packets with a dedicated line under each picture for indicating WTP in $€$ for one packet of $500 \mathrm{~g}$. At the end of each session, one of the elicited WTPs was randomly selected by each participant in order to determine whether this participant would have to buy one packet with their $€ 15$ indemnity (i.e., performance-based financial incentives). A purchasing price was also drawn at random between $€ 0.1$ and $€ 5$. Purchasing choices were enforced by the BDM procedure as follows:

If the selected WTP was smaller than the randomly drawn price, the participant did not purchase one unit.

If the WTP was higher than the randomly drawn price, the participant purchased the packet at the randomly drawn price. This price was withdrawn from the $€ 15$ indemnity.

This BDM mechanism was carefully explained in a trial round at the beginning of the experiment. During these explanations, we made clear that only one of the elicited WTPs 
will be randomly selected at the end of this experiment to determine whether participants will only have to buy one packet. During these initial explanations, the possibility of zero bids in the BDM procedure for avoiding the purchase of the good was carefully explained. During the initial explanations, no information was revealed to the participants regarding the distribution of the randomly selected purchasing price, which acted as the market price that was compared to the elicited WTP. This absence of revealing the distribution of the purchasing price avoided any future influence on the WTP.

We insisted on the participants' freedom to choose their WTP according to their preferences and the absence of bad or good replies. Simulations with a candy bar helped participants understand the mechanism.

\subsection{Explanatory Messages}

At rounds \#2, \#3, \#4, and \#5, explanatory messages were successively provided under different orders according to different groups. Based on agronomy and food science, short messages were favored for guaranteeing a relative efficiency in the information transmissions to consumers [28]. At rounds \#2 and \#3, two generic messages provided general information about lentils whatever the brands/labels of offered lentils. The generic messages encompass the health/nutritional message and the environmental/agronomic one.

The message on health and nutrition (revealed in rounds \#2 or \#3 depending on the groups of participants), was the following:

"Lentils are legumes that have many nutritional qualities. Lentils are cholesterol free, and they are low in fat and sodium. Lentils are naturally high in fiber, iron, folate and potassium which are important nutrients for the body. Eventually, lentils are a very good source of protein. As part of a balanced diet, the consumption of plant proteins, especially lentils, is recommended by nutritionists."

The message on environment and agronomy (revealed in round \#2 or \#3 depending on the groups of participants) was the following:

"The cultivation of legumes such as lentils has environmental benefits. No additional nitrogen fertilizer is needed for this lentil crop. Because with their leaves, they naturally capture nitrogen from the air and turn it into natural fertilizer in the soil, lentils provide an excellent crop precedent for subsequent crops. Lentil culture allows:

A yield gain of $10 \%$ on the following crop (wheat/corn),

Savings of 30 to $50 \%$ nitrogen fertilizers for the next crop (wheat/corn),

Improvement of the soil structure. The following Figure 2 summarizes these effects.

However, lentils are rarely cultivated in France due to the lack of sales opportunities, and/or the lack of organization in supply chains. Eating foods made from lentils would increase their share in French cultures."

Figure 2 inserted in this previous message and translated in English was found on the website of network of cooperatives, encompassing the COCEBI cooperative producing the OrganicELocal packet shown in Figure 1 [29].

These generic messages necessarily preceded the specific messages that were very precise and technically linked to specific products. At rounds \#4 and \#5, two specific messages provided additional details about the lentils with organic and/or local labels, namely the Organic packet at the center of Figure 1 and the Organic\&Local one called Paysans d'Ici on the right of Figure 1. The focus of the message tended to favor the Organic\&Local packet coming from an innovative cooperative. The specific messages encompass an intercropping message and a partnership one focusing on the Organic\&Local lentils. 


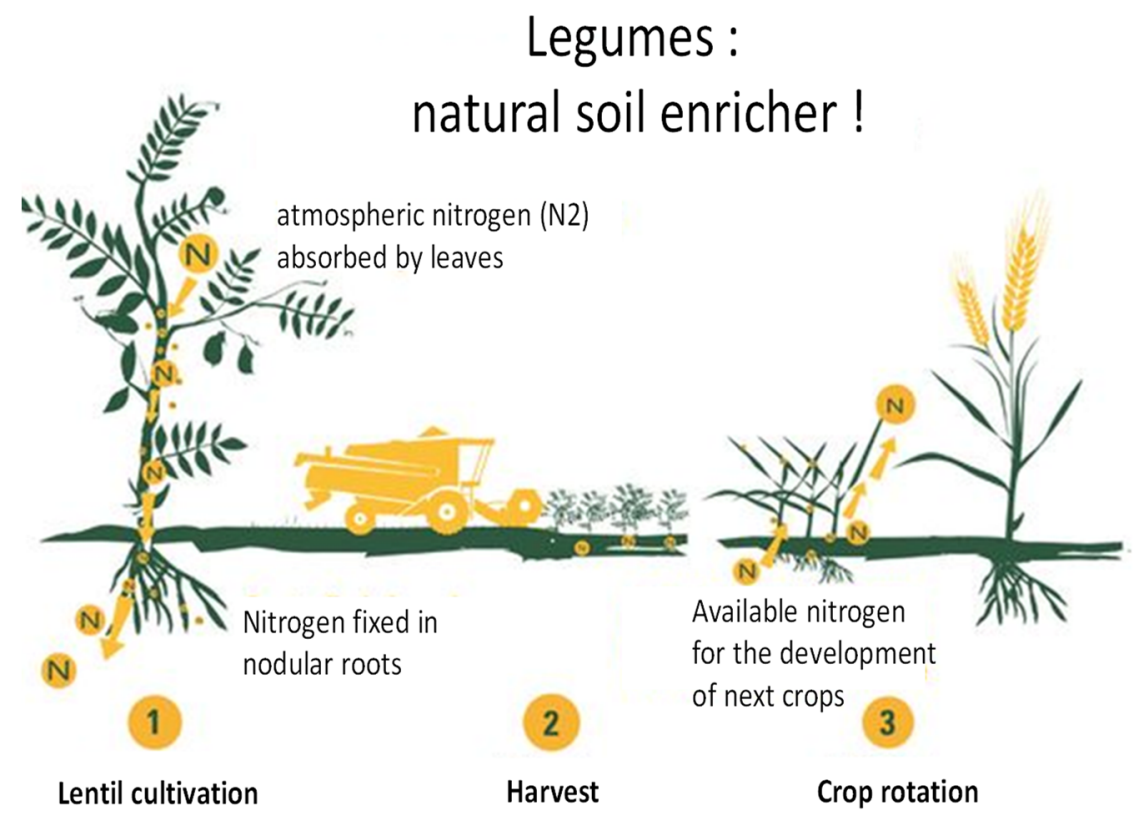

Figure 2. The nitrogen cycle with lentil cultivation.

The intercropping message (revealed in round \#4 or \#5 depending on the groups of participants) was as following:

"No synthetic, environmentally degrading pesticides are used in the production of organic lentils.

In addition, the Paysans d'Ici brand offers innovative practices for the environment and an ambitious crop diversification program. In agreement with certain farmers, the Paysans d'Ici brand is notably developing wheat-lentil combinations simultaneously grown on the same field. Such an association leads to better quality wheat, richer in protein, and to a more profitable wheat price for farmers."

The partnership message (revealed in round \#4 or \#5 depending on groups of participants) was as following:

"Encouraging farmers, through appropriate contracts and remunerative prices, is particularly important for the development of lentil cultivation.

The organic label contributes to the emergence of a sufficiently remunerative income for farmers.

In addition, the Paysans $d^{\prime} I c i$ brand is committed to establishing a fair trade partnership, in complete transparency with producers and consumers. This includes, in particular, a fair price paid to farmers, the payment of a development premium to farmers, direct commercial relations, a contractual commitment of at least 3 years between the farmers and the cooperative supplying the Paysans $d^{\prime} I c i$ brand. This fair partnership allows the development of lentil cultivation in Burgundy."

The order of the two first generic messages revealed at rounds \#2 and \#3 was precisely controlled by equally varying this order of messages across two different groups of participants. The order of the two specific messages revealed at rounds \#4 and \#5 was precisely controlled by equally varying this order of messages across two different groups of participants leading to four groups with their respective numbers of participants as shown in Table 2. Participants were randomly allocated to one of the four groups before coming to a session. We now turn to the results. 
Table 2. Groups with different orders of information revelation.

\begin{tabular}{lcc}
\hline \multirow{2}{*}{ Specific messages at rounds \#4 \& \#5 } & \multicolumn{2}{c}{ Generic Messages at rounds \#2 \& \#3 } \\
& $\begin{array}{c}\text { Health (\#2) } \\
\text { Environment (\#3) }\end{array}$ & $\begin{array}{c}\text { Health (\#3) } \\
\text { Intercropping (\#4) \& Partnership (\#5) }\end{array}$ \\
\hline Partnership (\#4) \& Intercropping (\#5) & 34 participants & 31 participants \\
\hline
\end{tabular}

\section{Results}

This section presents an analysis of WTPs. Figure 3 presents the average WTP for one packet with the tests for measuring significant differences in WTPs, using the Wilcoxon test for paired samples. The sign $\Delta$ indicates a significant difference between different products at a given round (by following the vertical line for a given round) and a significant difference for a same product between different rounds with additional messages (by following the related curves). The absence of a sign indicates the absence of significant effects. Rounds are represented on the X-axis and WTP in $€$ are represented on the Y-axis. Figure 3 shows average WTP, E(WTP), at the rounds \#1, \#3 (after the two generic messages) and \#5 (after the two specific messages focusing on the OrganicELocal lentils).

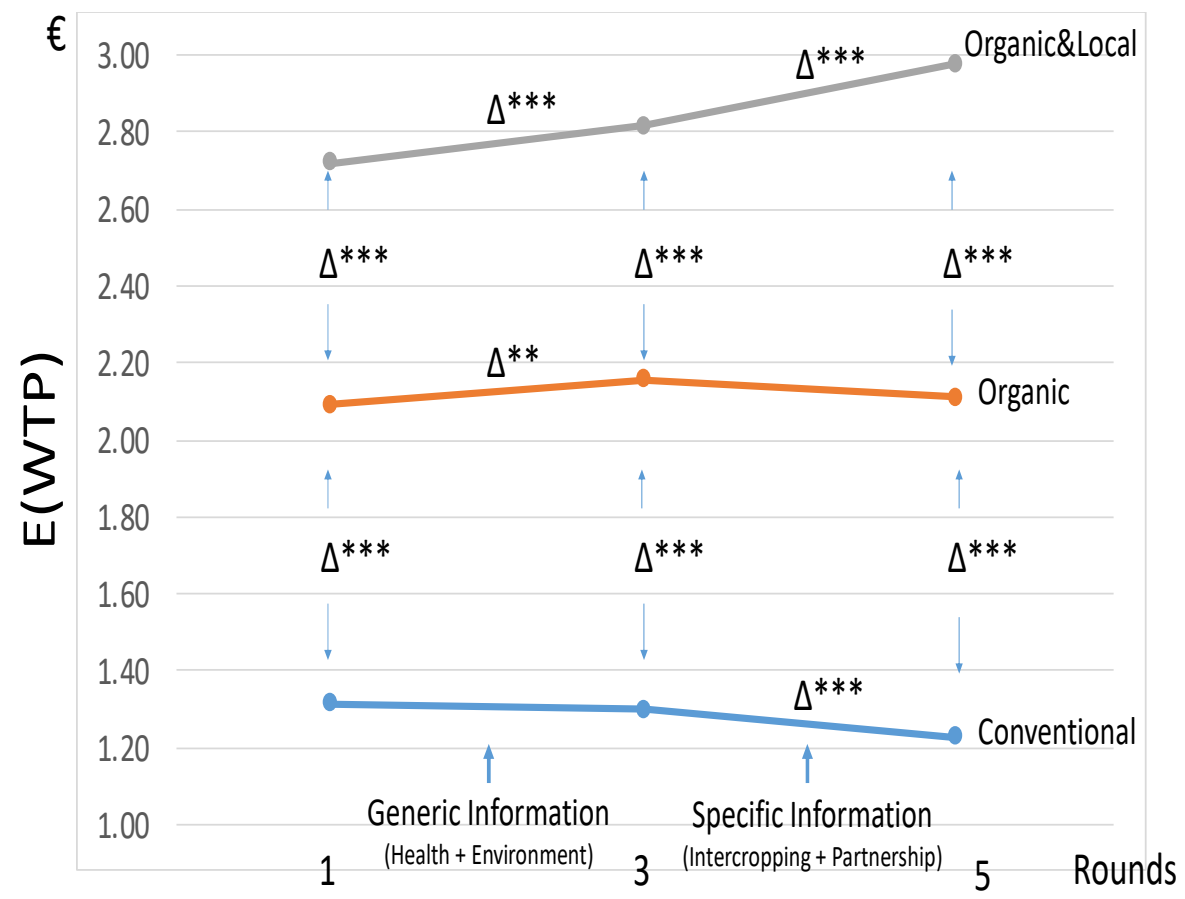

Figure 3. Average WTP for one packet of lentils. Note: 127 participants are taken into account. $\Delta^{* *}$ denotes significant difference at $5 \%$ and $\Delta^{* * *}$ denotes significant difference at $1 \%$ as tested by the Wilcoxon test for comparing paired sample WTP. For a given round, difference between the WTP for the Conventional and the Organic lentils and the WTP for Organic lentils and the Organic\&Local lentils are indicated between vertical arrows. For a given type of lentils, the significant impact of information is indicated by the $\Delta$ about the segments of different curves.

Figure 3 underlines that, without information at round \#1, there exists a strong and significant premium given to organic and/or local labels by participants. In other words, participants strongly value the environment and the absence of distance in the production indicated by the related labels. Before the revelation of any messages, this initial round of bids reveals that labels explain the strong difference between initial WTP for the different packets. These differences in WTP tend to reflect the hierarchy of average market prices P observed on the market at the time of the experiment, namely an average market price (compared to the average WTP, E(WTP)) equal to $\mathrm{P}=€ 0.79$ for Conventional lentils (com- 
pared to $E(W T P)=€ 1.32), P=€ 1.93$ for Organic lentils (compared to $E(W T P)=€ 2.10$ ), and $\mathrm{P}=€ 2.80$ for the Organic\&Local lentils (compared to $\mathrm{E}(\mathrm{WTP})=€ 2.72$ ).

Figure 3 also shows that the Generic Information revealed at stages \#2 and \#3 significantly influences the WTPs for packets with labels, namely the Organic one and the Organic\&Local one. This effect is weak, since the relative variation of WTP between periods 1 and 3 is equal to $3.1 \%$ for the Organic lentils and to $3.5 \%$ for the Organic\&Local lentils. This information does not influence the WTP for the Conventional lentils. The Generic Information is particularly compatible with labels, in particular the organic one signaling an environmental benefit. Figure 3 underlines a significant influence of generic information with both types of messages on WTP, even if this influence is weak. The existing labels reinforce the social desirability of the message underscoring the sustainability of lentils via nutritional and environmental information [30].

Figure 3 also underlines the role of the Specific messages revealed between rounds \#3 and \#5. This information only impacts the WTP for the Organic\&Local lentils directly concerned by the messages. This effect is also weak, since the relative variation of WTP between periods 3 and 5 is equal to $5.7 \%$ for the OrganicELocal lentils, with $52.7 \%$ of participants who increase their WTP for this high-quality product. The Specific Information reinforces the positive perception of the high-quality products by consumers.

Next, some econometric estimations based on a random Tobit estimator with dummy variables that represent different messages partially confirm the results of Figure 3 . The econometric estimation of WTP is presented in Table 3 to measure the impact of different messages represented by dummy variables (DV). We pooled the observations corresponding to participants' WTPs elicited in the successive rounds \#1,\#3, and \#5. For each participant, a total of nine WTPs were taken into account, corresponding to the three rounds for the three products. Given that each participant $i$ wrote several WTPs for several products, errors related to these WTPs are potentially correlated to each participant. The random effect imposes constraints on the structure of the variance-covariance matrix. Furthermore, a WTP cannot be negative and is left-censored at zero, which is why we use the random effects Tobit estimator. We used the $\mathrm{R}$ package pglm that approximates the likelihood function via a Gauss-Hermite quadrature [31].

Each product (Conventional/Organic/Organic\&Local) is identified by a dummy variable (DV) equal to 1 for a given product, and zero otherwise. The type of information shared in a given round is also identified by a DV equal to 1 when it is shared before the WTP elicitation in a given round (and 0 otherwise). Thus, the DV Generic Info is equal to 1 for WTP elicited at round\#3, and 0 otherwise. The DV Specific Info is equal to 1 for WTP elicited at round\#5, and 0 otherwise. In a first model, the regression only takes into account these DV for isolating the time of the WTP elicitation with the products characteristics and the information. A second model considers the previous variables and explores participants' perceptions and socioeconomic characteristics. We tested the impact of these variables, and we only report one regression with only the significant variables. When these variables do not significantly impact WTP, we re-run a final regression without these variables and with only significant perceptions and sociodemographic variables.

Table 3 presents the two regressions that measure the effects of generic information and specific information on the WTP for one packet of lentils. For each participant and each product, we only consider three rounds, namely the first round without any message, round \#3 when the two generic messages were revealed, and round \#5 when the two specific messages were revealed. The coefficients linked to a product and the coefficient linked to a precise type of information measure the WTP of this product after the revelation of information.

Table 3 underlines the strong differences in WTP between the different packets at round \#1. At the initial round without additional information, the estimated coefficients related to the DV Conventional, Organic and Organic\&Local are statistically significant (namely, indicated by ${ }^{* * *}$ ). The estimated coefficients related to the DV Conventional (equal to 1.06 in model 1), Organic (equal to 1.86 in model 1), and Organic\&Local (equal to 2.51 
in model 1) reproduce the results of Figure 3, namely the WTP hierarchy between these products. Table 3 also shows that the Generic Information has no statistical influence, which differs from Figure 3, a result that will be mitigated in Table 4. This absence of significant effect of Generic Information is explained by the variance of WTP variations following the revelation of information. However, the Specific Information only has a significant influence on the WTP for Organic\&Local lentils, which confirms the results of Figure 3. A possible explanation for this increase in WTP for this "green" product, following the revelation of specific message, refers to the halo effect that is the tendency for which consumers tend to be influenced by their initial judgment regarding the hierarchy of products, for judging the importance of additional messages.

Table 3. Estimation of pooled WTP elicited at rounds \# 1, 3 \& 5 for one packet of lentils with a Tobit random effects estimator.

\begin{tabular}{|c|c|c|c|c|}
\hline \multirow{3}{*}{$\begin{array}{l}\text { Independent Variables } \\
\text { Conventional }\end{array}$} & \multirow{2}{*}{\multicolumn{2}{|c|}{$\begin{array}{c}\text { WTP for } 1 \text { Packet } \\
\text { Model } 1\end{array}$}} & \multirow{2}{*}{\multicolumn{2}{|c|}{$\frac{\text { WTP for } 1 \text { Packet }}{\text { Model } 2}$}} \\
\hline & & & & \\
\hline & $1.06^{* * *}$ & $(0.06)$ & $0.99 * * *$ & $(0.07)$ \\
\hline Conventional $\times$ Generic Info & -0.01 & $(0.07)$ & -0.01 & $(0.07)$ \\
\hline Conventional $\times$ Specific Info & -0.10 & $(0.07)$ & -0.10 & $(0.07)$ \\
\hline Organic & $1.86^{* * *}$ & $(0.06)$ & $1.80 * * *$ & $(0.07)$ \\
\hline Organic $\times$ Generic Info & 0.06 & $(0.07)$ & 0.06 & $(0.07)$ \\
\hline Organic $\times$ Specific Info & 0.01 & $(0.07)$ & 0.01 & $(0.07)$ \\
\hline Organic\&Local & $2.51^{* * *}$ & $(0.06)$ & $2.44^{* * *}$ & $(0.07)$ \\
\hline Organic\&Local $\times$ Generic Info & 0.09 & $(0.07)$ & 0.09 & $(0.07)$ \\
\hline Organic\&Local $\times$ Specific Info & $0.25^{* * *}$ & $(0.07)$ & $0.25^{* * *}$ & $(0.07)$ \\
\hline Strong Meat Consumption ${ }^{a}$ & & & $-0.39 * * *$ & $(0.04)$ \\
\hline Eating Less Meat in 10 years $b$ & & & $0.16^{* * *}$ & $(0.06)$ \\
\hline Women $^{\mathrm{c}}$ & & & $0.29^{* * *}$ & $(0.05)$ \\
\hline Low Income ${ }^{d}$ & & & $-0.12 * * *$ & $(0.02)$ \\
\hline Stand. devi $\varepsilon$ e & $0.57^{* * *}$ & $(0.01)$ & $0.54^{* * *}$ & $(0.01)$ \\
\hline Stand. dev. $\mu^{\mathrm{f}}$ & $0.82^{* * *}$ & $(0.02)$ & $0.83^{* * *}$ & $(0.02)$ \\
\hline Observations & \multicolumn{2}{|c|}{$\mathrm{N}=1143$} & \multicolumn{2}{|c|}{$N=1143$} \\
\hline Log likelihood & \multicolumn{2}{|c|}{-1137.7} & \multicolumn{2}{|c|}{-1077.9} \\
\hline
\end{tabular}

Note: ${ }^{* * *}$ : significant at $1 \%$. Standard errors in parentheses. From the Exit Questionnaire: ${ }^{a}$ DV equal to 1 if a participant eats meat once per day or more than once per day, ${ }^{b}$ DV equal to 1 if a participant estimated that in 10 years she/he will eat less meat than today or eating no meat anymore, ${ }^{\mathrm{c}}$ DV equal to 1 if a woman and ${ }^{\mathrm{d}} \mathrm{DV}$ equal to 1 if the monthly household income is lower than $€ 2000$. ${ }^{e}$ Standard deviation related to the random effect of the estimator. ${ }^{\mathrm{f}}$ Standard deviation related to the tobit part of the estimator.

In Table 3, results of model 1 are consistent with results of model 2, which integrates perceptions and sociodemographic variables. Model 2 shows the role of various variables that influence the WTP at round \# 1, particularly like the meat consumption habit. The consumers have a higher WTP for lentils whatever the product at round \#1, if they have low habits regarding meat consumption (see the negative coefficient linked to the strong meat consumption) and if they think they will eat less meat in 10 years compared to today. This result underlines the importance of the meat consumption as a significant marker regarding the WTP for potentially alternative sustainable products like lentils. Eventually, results of Table 3 are robust when we consider the five rounds of WTP elicitation and the different orders of information (see Table 2). 
Table 4. Estimation of pooled WTP elicited at rounds \#1 \& \#2 for one packet of lentils with a Tobit random effects estimator.

\begin{tabular}{|c|c|c|}
\hline \multirow{2}{*}{ Independent Variables } & \multicolumn{2}{|c|}{ WTP for 1 Packet } \\
\hline & \multicolumn{2}{|c|}{ Model 1} \\
\hline Conventional & $1.31^{* * *}$ & $(0.05)$ \\
\hline Conventional $\times$ Health & -0.05 & $(0.08)$ \\
\hline Conventional $\times$ Environment & 0.08 & $(0.08)$ \\
\hline Organic & $2.11^{* * *}$ & $(0.05)$ \\
\hline Organic $\times$ Health & -0.07 & $(0.08)$ \\
\hline Organic $\times$ Environment & $0.15^{* *}$ & $(0.08)$ \\
\hline Organic\&Local & $2.75^{* * *}$ & $(0.05)$ \\
\hline Organic\&Local $\times$ Health & -0.06 & $(0.08)$ \\
\hline Organic\&Local $\times$ Environment & $0.16^{* *}$ & $(0.08)$ \\
\hline Stand. Devi. $\varepsilon^{a}$ & $0.50^{* * *}$ & $(0.01)$ \\
\hline Stand. dev. $\mu^{\mathrm{b}}$ & $0.75^{* * *}$ & $(0.02)$ \\
\hline Observations & \multirow{2}{*}{\multicolumn{2}{|c|}{$\begin{array}{c}N=762 \\
-731.5\end{array}$}} \\
\hline Log likelihood & & \\
\hline
\end{tabular}

Going further with Table 4, we also focus on the impact of the first round of information only, for measuring the impact of the initial information at round \#2, without any interference from subsequent messages. At round \#2, the DV Health is equal to 1 for WTP elicited after the message on Health (and nutrition), and 0 otherwise. The DV Environment is equal to 1 for WTP elicited after the message on Environment (and crop rotation), and 0 otherwise. Table 4 shows the impact of these different types of messages on WTP for different packets, with DV similar to the ones of Table 3 for the different types of products, Conventional, Organic, and Organic\&Local.

Table 4 indicates a significant effect of the message about Environment (and crop rotation) on both packets with the organic label (namely, Organic and Organic\&Local). No significant effect is observed on the Conventional product. Moreover, the message about Health (and nutrition) has no significant effect, which is remarkable and differs from previous experiments, underlining the higher values of health characteristics compared to values for environmental characteristics [32]. As a possible explanation, it should be noted that the message on health mainly describes nutritional benefits concerning the product, but with strong implications for the general diet including many foods, while the WTP elicitation only concerns the three specific packets of lentils. Even if the Environmental message reinforces the positive image of the organic label posted on two packets (Organic and Organic\&Local), the effect of this message on WTP is relatively weak.

The WTP elicitation was complemented by other questions regarding the participants' perception in the exit questionnaire, namely after the revelation about all messages. Table 5 shows the replies to some questions that help understand the consumer's perception.

Table 5 particularly reveals a significant sensitivity to sustainable issues, following the revelation of all messages at the end of round \#5. Indeed, 58.7\% of participants declare they plan to eat more pulses in the future, which are intents and not concrete changes in purchasing habits. However, these $58.7 \%$ underline an interest in the issues such as crops diversification and legumes consumptions, which can justify regulatory interventions for favoring crops diversification and boosting legumes production. Sixty percent of consumers deem the replacement of animal proteins by plant-based proteins possible, suggesting a significant awareness of future challenges. Such an awareness captures sensitivities and possible intents rather than concrete changes in behaviors, depending on many parameters related to supply and demand characteristics. Moreover, Table 5 shows that many participants are aware of challenges regarding the future and the sustainability of meat. Eventually, consumers mention a possible inefficiency of foods labels to signal 
quality, because of their proliferation (as indicated at the bottom of Table 5). This issue of labels for promoting diversity is now tackled in the discussion.

Table 5. Possible changes in consumption declared after the revelation of all messages ${ }^{\text {a }}$.

\begin{tabular}{lc}
\hline & \% of Yes \\
\hline $\begin{array}{l}\text { After the revelations of information, I plan to } \\
\text { eat more pulses in the future }\end{array}$ & 58.7 \\
$\begin{array}{l}\text { Partial replacement of animal proteins by } \\
\text { plant-based proteins is possible }\end{array}$ & 60.3 \\
$\begin{array}{l}\text { Sustainable standards should be imposed for } \\
\text { meat }\end{array}$ & 93.7 \\
$\begin{array}{l}\text { In } 10 \text { years, my meat consumption will be } \\
\text { lower than today (or null) }\end{array}$ & 77.1 \\
$\begin{array}{l}\text { Quality labels for foods are often inefficient, } \\
\text { because they are too complex to interpret } \\
\text { because they are too many }\end{array}$ & 46.5 \\
\hline $\begin{array}{l}\text { Note: a From the Exit Questionnaire } \\
\quad\end{array}$
\end{tabular}

\section{Discussion}

The findings of this study can help inform policy decisions seeking to promote sustainability and crop diversification by influencing consumer choices. Before any information was provided, initial WTP differed markedly among the lentil types as a result of their labeling (Figure 3). After the participants received the generic and specific messages, a weak positive effect was seen in WTP for the lentils with the organic and local production labels but not for the label-free lentils. More subtle responses like the ones we observed here may have been obscured in past research, where the focus was placed on broader recommendations directed at entire categories of foods like meat, fruit, vegetables, or legumes [13,33], ignoring differences in production quality and in quality labels.

The generic information included in official recommendations should be able to boost labeling systems conveying production quality (e.g., organic/local) by generating a halo effect. For example, given the influence of environmental messaging observed in this study, consumers may be encouraged in their purchasing decisions by the presence of quality labels on products. Generic marketing campaigns could be launched to promote legume consumption, even if the short-term effects on legume sales may be limited. Both generic and specific information can positively reinforce how consumers perceive high-quality lentils. Some participants were receptive to the specific informational messages discussing producer partnerships and the development of fair-trade contracts between farmers and processors (see the last message in sub-Section 2.5 and Figure 3). The difficulty to define precise contracts and favor economic incentives in the supply chain for offering plant-based proteins is one major reason for the limited cultivation of lentils in France and Europe [34].

Even if consumers have a positive perception of organically and locally produced lentils, this attitude will not necessarily translate into the systematic purchases of such lentil types. This weakness of purchases can be reinforced by two additional effects. First, the durability of revealed information via recommendations or generic advertising is likely to quickly fade after some time, since consumers are constantly exposed to new information and/or are characterized by an imperfect recall. The proliferation of information drastically reduces the efficiency of any additional recommendation. Second, generic information could/should also focus on legumes including not only lentils, but also beans, peas, chickpeas, faba beans ( ... ), which would make difficult the translation of such general information on legumes into a specific purchase of lentils, beans or peas. Revealing information on one broad category of foods, like legumes, could limit a possible significant effect on purchases of each product, like lentils, since this general information could become vague when consumers would face each specific product in supermarkets. The limitation of the present paper is that it examined how generic and precise messages affected participants' WTP for lentils only, and not for legumes in general. 
In this study, we presented participants with three products that reflected common options in French supermarkets. The WTP results show that participants preferred the lentils with the organic and local production labels (Figure 3), even if these preferences are perhaps not always expressed in real life because of financial constraints. Further developing legume labeling systems could be one way to promote increased crop diversification, longer crop rotations, and the use of intercropping. In this regard, significant differences exist between organic farming practices and conventional farming practices; notably, crop rotations last 15\% longer in organic farming systems [3]. Encouraging such practices and sharing technical knowledge about organic practices with farmers could be prioritized. An additional boost could be provided by establishing official targets-for example, declaring that $50-70 \%$ of legume production in France should be organic by 2030; when our experiment was conducted, in 2020, this figure was 34\% [35].

Perhaps some thought should be given to creating an additional labeling system that goes beyond the organic labeling system and that indicates a commitment to crop diversification (i.e., in the form of longer rotations or intercropping). The main challenge is to succinctly convey why crop diversification is better than other strategies when it comes to environmental effects. It might possible to develop a new label, like the "Blanc Bleu Coeur" label (e.g., applied in France when linseeds are used as animal feed), although the latter endeavor was the product of a whole supply chain financing many marketing campaigns [36]. Creating a new label that will have an appreciable influence on consumer purchases is challenging because, as labels proliferate, it will become increasingly difficult to build a reputation [37]. Moreover, many labels aimed at communicating product sustainability do not significantly affect food choices [38]. Consequently, the most efficient and effective approach may be to reinforce and promote existing organic and local production labeling systems, which already benefit from consumer recognition, instead of developing new labels to specifically signal the use of crop diversification.

Based on the results of our study, policymakers should look beyond generic recommendations and quality labels to change consumer choices and boost crop diversification; indeed, we found that the informational messages had only a weak effect on WTP (Figure 3 and Table 3). The alternative solutions for the policy maker would consist in focusing on agricultural systems. Policymakers should consider other instruments instead, like the support of agronomic R\&D and/or some specific subsidies to farmers for growing legumes and beefing up crop diversifications.

The European policy makers could follow the example of Canada, being a major producer of lentils [39]. Beyond lentils, the expansion of the Canadian legume industry over the last 30 years was closely related to the attention given to the farmers' profitability, the research into new varieties that resist diseases, and the growth of processing facilities. The majority of new legume varieties in Canada have been developed via public breeding programs, funded through private-public check-offs paid by farmers in exchange for free access to the new varieties [39]. Alternatively, there are also about 23 million acres of alfalfa in the US, with the benefits of alfalfa in crop rotation being important and guaranteeing decent profits for farmers [40].

Mimicking these foreign initiatives and transitioning towards a sustainable agriculture on a large scale in Europe would require long adaptive changes through experimenting and learning by farmers. The policy could start from innovation niches devising sustainable processes able to secure the incomes of farmers taking some risks with the choice of legumes crops, as the mechanism developed by the COCEBI cooperative producing the third packet Organic\&Local offered in our experiment (see Figure 1). Figure 3 shows that consumers value the development of decent incomes for famers (see Figure 3 and the impact of the specific messages mentioning the partnership with farmers on WTP).

Considerations of farmers' incomes could lead to the possible development of new farm subsidies influencing crop diversifications and/or legumes cultivation. However, as Europe operates in an open economy with global markets, public subsidies to farmers would be scrutinized through trade regulation, for knowing if they would be considered 
as illegitimate trade advantages according to the rules of the World Trade Organization (WTO). In other words, a special support to producers is likely to lead to distortions of competition and problems with trade agreements, in particular if this support is only linked to a specific crop like lentils. However, if a possible public support was only related to crops diversification, this support could be deemed as legitimate from the WTO perspective, since it would be related to environmental targets.

Beyond these technical considerations, solutions dedicated to farmers and agricultural systems should be combined with recommendations and quality labels focusing on consumer choices, which is the topic of this paper.

\section{Conclusions}

Despite the limitations of these experimental results, we were able to shed light on an important issue by showing how consumers may respond to generic and specific messages about the benefits of lentils. When WTP were measured after the participants had received the generic and specific informational messages, we observed a weak but significant influence for the lentils with organic and local production labels. There was no effect for the lentils without any production labels. These results underline the importance of quality labels for promoting crops diversification. It seems plausible that further developing organic and local production labels for legumes could drive action toward lengthening crop rotations and boosting crop diversification.

Extensions and new studies should address some limitations of this study. New studies could examine whether or not generic messages revealed to consumers should focus on legumes presented as a general category, rather than on specific products like lentils (as studied in this paper). Future research could build upon these findings by evaluating WTP via other methodologies, such as field experiments conducted in supermarkets where consumers are directly exposed to recommendations, advertising, and product promotion. Beyond limitations of economic experiments, our paper underlined that the development of legumes and crops diversification should also rely on consumers' involvement.

Funding: This research was funded by the European Union's Horizon 2020 research and innovation program under the grant agreement No 727482, DiverIMPACTS, and by the French Agence Nationale de la Recherche (ANR) under the grant agreement DIETPLUS ANR-17-CE21-0003. The funders had no role in study design, data collection and analysis, decision to publish, or preparation of the manuscript. The authors only are responsible for any omissions or deficiencies.

Institutional Review Board Statement: The study was conducted according to the guidelines of the Declaration of Helsinki, and approved by the Institutional Review Board of Centre National de la Recherche Scientifique -CNRS- Certificate 2-19079 \UMR6265. The Chemosens PanelSens database used for the recruitment has been declared to the Commission Nationale Informatique et Libertés-CNIL-Certificate $n^{\circ} 1148039$.

Informed Consent Statement: Informed consent was obtained from all subjects involved in the study.

Data Availability Statement: Data may be provided upon request.

Acknowledgments: The author thanks Christophe Martin and Noé Gouyette for their help.

Conflicts of Interest: The author declares no conflict of interest.

\section{References}

1. Lin, B. Resilience in agriculture through crop diversification: Adaptive management for environmental change. BioScience 2011, 61, 183-193. [CrossRef]

2. IPCC (The Intergovernmental Panel on Climate Change). Climate Change and Land: An IPCC Special Report on Climate Change, Desertification, Land Degradation, Sustainable Land Management, Food Security, and Greenhouse Gas Fluxes in Terrestrial Ecosystems; IPCC: Geneva, Switzerland, 2019. Available online: https://www.ipcc.ch/srccl/ (accessed on 12 March 2021).

3. Barbieri, P.; Pellerin, S.; Nesme, T. Comparing crop rotations between organic and conventional farming. Sci. Rep. 2017, 7, 13761. [CrossRef]

4. Anglade, J.; Billen, G.; Garnier, J. Relationships for estimating N2 fixation in legumes: Incidence for N balance of legume-based cropping systems in Europe. Ecosphere 2015, 6, 1-24. [CrossRef] 
5. Magrini, M.-B.; Anton, M.; Chardigny, J.-M.; Duc, G.; Duru, M.; Jeuffroy, M.-H.; Meynard, J.-M.; Micard, V.; Walrand, S. Pulses for sustainability: Breaking agriculture and food sectors out of lock-in. Front. Sustain. Food Syst. 2018, 2, 64. [CrossRef]

6. Morel, K.; Revoyron, E.; San Cristobal, M.; Baret, P.V. Innovating within or outside dominant food systems? Different challenges for contrasting crop diversification strategies in Europe. PLoS ONE 2020, 15, e0229910. [CrossRef]

7. Figueira, N.; Curtain, F.; Beck, E.; Grafenauer, S. Consumer Understanding and Culinary Use of Legumes in Australia. Nutrients 2019, 11, 1575. [CrossRef] [PubMed]

8. Dahl, W.J.; Foster, L.M.; Tyler, R.T. Review of the health benefits of peas (Pisum sativum L.). Br. J. Nutr. 2012, 108 (Suppl. S1), S3-S10. [CrossRef]

9. Melendrez-Ruiz, J.; Arvisenet, G.; Laugel, V.; Chambaron, S.; Monnery-Patris, S. Do French consumers have the same social representations of pulses as food industry professionals? Foods 2020, 9, 147. [CrossRef]

10. Cordis. Final Report Summary-EUROLEGUME. Enhancing of Legumes Growing in Europe through Sustainable Cropping for Protein Supply for Food and Feed. European Commission. 2017. Available online: https://cordis.europa.eu/project/id/613781 / reporting/de (accessed on 12 March 2021).

11. Hartmann, C.; Siegrist, M. Consumer perception and behaviour regarding sustainable protein consumption: A systematic review. Trends Food Sci. Technol. 2017, 61, 11-25. [CrossRef]

12. Lock, K.; Smith, R.D.; Dangour, A.D.; Keogh-Brown, M.; Pigatto, G.; Hawkes, C.; Fisberg, R.M.; Chalabi, Z. Health, agricultural, and economic effects of adoption of healthy diet recommendations. Lancet 2010, 376, 1699-1709. [CrossRef]

13. Willett, W.; Rockström, J.; Loken, B.; Springmann, M.; Lang, T.; Vermeulen, S.; Garnett, T.; Tilman, D.; DeClerck, F.; Wood, A.; et al. Food in the anthropocene: The eat-lancet commission on healthy diets from sustainable food systems. Lancet 2019, 393, 447-492. [CrossRef]

14. Irz, X.; Leroy, P.; Réquillart, V.; Soler, L.G. Economic assessment of nutritional recommendations. J. Health Econ. 2015, 39, 188-210. [CrossRef] [PubMed]

15. Marette, S.; Réquillart, V. Dietary models and challenges for economics. Rev. Agric. Food Environ. Stud. 2020, 101, 5-22. [CrossRef]

16. Marette, S.; Roosen, J.; Blanchemanche, S. The Combination of Lab and Field Experiments for Benefit-Cost Analysis. J. Benefit-Cost Anal. 2011, 2, 1-35. [CrossRef]

17. Becker, G.M.; DeGroot, M.H.; Marschak, J. Measuring Utility by a Single-Response Sequential Method. Behav. Sci. 1964, 9, 226-232. [CrossRef] [PubMed]

18. De Boer, J.; Schösler, H.; Boersema, J. Motivational differences in food orientation and the choice of snacks made from lentils, locusts, seaweed or "hybrid" meat. Food Qual. Prefer. 2013, 28, 32-35. [CrossRef]

19. Slade, P. If you build it, will they eat it? Consumer preferences for plant-based and cultured meat burgers. Appetite 2018, 125, 428-437. [CrossRef]

20. Martin, C.; Lange, C.; Marette, S. Importance of additional information, as a complement to information coming from packaging, to promote meat substitutes: A case study on a sausage based on vegetable proteins. Food Qual. Prefer. 2021, 87, art 104058. [CrossRef]

21. Saint-Eve, A.; Irlinger, F.; Pénicaud, C.; Souchon, I.; Marette, S. Consumer preferences for new fermented food products that mix animal and plant protein sources. Food Qual. Prefer. 2021, 90, art 104117. [CrossRef]

22. Meier, C.; Oehen, B. Consumers' Valuation of Farmers' Varieties for Food System Diversity. Sustainability 2019, 11, 7134. [CrossRef]

23. Alcon, F.; Marin-Minano, C.; Zabala, J.A.; de-Miguel, M.D.; Martinez-Paz, J.M. Valuing diversification benefits through intercropping in Mediterranean agroecosystems: A choice experiment approach. Ecol. Econ. 2020, 171, 106593. [CrossRef]

24. Crespi, J.; Marette, S. Generic Commodity Promotion and Product Differentiation. Am. J. Agric. Econ. 2002, 84, 691-701. [CrossRef]

25. Chakravarti, A.; Janiszewski, C. The Influence of Generic Advertising on Brand Preferences. J. Consum. Res. 2004, 30, 487-502. [CrossRef]

26. Crespi, J. Generic Advertising and Product Differentiation Revisited. J. Agric. Food Ind. Organ. 2007, 5, 1-21. [CrossRef]

27. Mitchell, D.C.; Lawrence, F.R.; Hartman, T.J.; Curran, J.M. Consumption of dry beans, peas, and lentils could improve diet quality in the US population. J. Am. Diet. Assoc. 2009, 109, 909-913. [CrossRef]

28. Keller, K.L.; Staelin, R. Assessing biases in measuring decision effectiveness and information overload. J. Consum. Res. 1989, 15, 504-508. [CrossRef]

29. Ethiquable. Légumineuses Equitables et bio avec Paysans d'Ici. Available online: https://www.ethiquable.coop/page-dactualitesmag/7-legumineuses-equitables-bio-avec-paysans-dici (accessed on 12 March 2021).

30. Cerri, J.; Thøgersen, J.; Testa, F. Social desirability and sustainable food research: A systematic literature review. Food Qual. Prefer. 2019, 71, 136-140. [CrossRef]

31. Croissant, Y. Package Pglm: Panel Generalized Linear Models, R package version 0.2-1. 2017. Available online: https:/ /cran.rproject.org/web/packages/pglm/pglm.pdf (accessed on 12 March 2021).

32. Lusk, J.L.; Shogren, J.F. Experimental Auctions. Methods and Applications in Economic and Marketing Research; Cambridge University Press: Cambridge, UK, 2007.

33. Tilman, D.; Clark, M. Global diets link environmental sustainability and human health. Nature 2014, 515, 518-522. [CrossRef]

34. Magrini, M.-B.; Anton, M.; Cholez, C.; Corre-Hellou, G.; Duc, G.; Jeuffroy, M.H.; Meynard, J.M.; Pelzer, E.; Voisin, A.-S.; Walrand, $\mathrm{S}$. Why are grain-legumes rarely present in cropping systems despite their environmental and nutritional benefits? Analyzing lock-in in the French agrifood system. Ecol. Econ. 2016, 126, 152-162. [CrossRef] 
35. Agence Bio. La Consommation Bio en Hausse en 2019 Stimule la Production et la Structuration des filières françaises. Les chiffres 2019 du Secteur bio Dossier de Presse-9 Juillet; Agence Bio: Paris, France, 2020. Available online: https://www.agencebio.org/wp-content/ uploads/2020/07/DP-AGENCE-BIO-CHIFFRES-2019_def.pdf (accessed on 12 March 2021).

36. Marette, S.; Millet, G. Economic Benefits from Promoting Linseed in the Diet of Dairy Cows for Reducing Methane Emissions and Improving Milk Quality. Food Policy 2014, 46, 140-149. [CrossRef]

37. Yokessa, M.; Marette, S. A Review of Eco-labels and their Economic Impact. Int. Rev. Environ. Resour. Econ. 2019, 13, 1-45. [CrossRef]

38. Grunert, K.; Hieke, S.; Wills, J. Sustainability labels currently do not play a major role in consumers' food choices. Food Policy 2014, 44, 177-189. [CrossRef]

39. Bekkering, E. Pulses in Canada. Statistics Canada, Catalogue 96-325-XWE. 2015. Available online: https://www150.statcan.gc. $\mathrm{ca} / \mathrm{n} 1 /$ pub/96-325-x/2014001/article/14041-eng.htm (accessed on 12 March 2021).

40. Smith, R. Value of Alfalfa in Rotation; University of Kentucky Cooperative Extension, Service: Lexington, KY, USA, 2010. 